\title{
LOS MITOS COMO PARTE DEL SISTEMA DE CREENCIAS DE LOS INDÍGENAS DE BAJA CALIFORNIA
}

\author{
Por \\ Julia Bendimez Patterson* \\ Raúl Navejas**
}

\section{RESUMEN}

Los indígenas de la península tenían sistemas de creencias, mitos y rituales que conjuntamente se pueden definir como una religión o religiones. En este trabajo se examinan particularmente los mitos y algunos rituales como parte de la cosmovisión de los californios.

\begin{abstract}
The indians of the peninsula had systems of beliefs, myths and rituals that in all can be defined as being a religion or religions. In this article we examine particularly myths and rituals as a part of the world view of the californios or indians of the peninsula.
\end{abstract}

\section{INTRODUCCIÓN}

Vivimos en tiempos remotamente distantes de la época en la cual habitaban, libres y dueños de este territorio, indígenas de diversas lenguas y culturas cuya visión del mundo y origen no podemos más que entrever a partir de algunas evidencias arqueológicas, fuentes escritas misionales y registros etnográficos.

Antes de la llegada de los europeos, sólo en la región que comprendía las sociedades cochimí, guaicura y pericú se calcula una población de 40 a 50 mil habitantes (Grijalba, 1982:47; Piñera, 1978:49). Al norte de éstas habitaban por lo menos decenas de miles más. La diversidad de cosmovisiones entre estos grupos debió haber existido y es sutilmente perceptible entre sus costumbres y mitos.

Estas diferencias son atribuibles a razones históricas y factores intrínsecos a la evolución social y cultural de cada uno de los núcleos lingüísticos

\footnotetext{
* Arqué́loga directora del INAH de Baja California e investigadora en el Instituto de Investigaciones Sociales de la UABC.

* Licenciado en lengua y literatura hispánica, actualmente labora en el Instituto de Geografía e Historia de la UABC.
} 
(v.g. cochimí, paipai, kumiai y guaicura), como lo es la difusión y adopción de creencias religiosas de sociedades hacia el norte o quizá de la tierra hacia el este, al otro lado del golfo de California. Un ejemplo de lo anterior que podemos citar es lo relacionado con lo que Ken Hedges (1970:21) denomina religión "Chungichnish". Hedges observa en base a las investigaciones de Waterman (1910:274-278) que este conjunto de creencias y ritos que involucraba el consumo del toloache entre los adolescentes, arribó al sur de California y norte de Baja California desde la zona de las islas Catarina (en California) en tiempos postcontacto y probablemente hacia la segunda mitad del siglo XVIII, influyendo en la "religión básica" de los indígenas de la región que eran de la lengua kumiai.

Las misiones de la orden de Loyola, entre 1697 y 1776, dedicaron interés a la conformación religiosa de los aborígenes de las tres cuartas partes del sur de la península. Así se tienen testimonios de Segismundo Tarraval, Fernando Consag, Francisco Javier Clavijero, Miguel Venegas, Juan Jacobo Baegert, Benno Ducrue y Miguel del Barco. Luis Sales fue aparentemente el único dominico que se preocupó por consignar información sobre la religión aborigen entre 1770 y 1834 .

El extremo norte de la península fue el lugar donde algunos investigadores de fines del siglo XIX y durante el presente reunieron datos sobre este aspecto de las sociedades yumanas que habitaban en la región. De esta forma tenemos los trabajos de Constance Dubois, T.T. Waterman, Peveril Meigs, Ralph Michelsen y William Kelley entre otros.

En este documento analizaremos algunos mitos de creación o cosmogénesis de los indígenas pericú, guaicura, cochimí, kumiai, kiliwa, cucapá y paipai.

\section{EL MITO}

Todas las sociedades antiguas y contemporáneas tienen sistemas organizados de ceremonias, rituales y mitos que conforman lo que denominamos religión.

De cualquier modo que el hombre defina el universo, en todas partes emplea la religión para encontrarse y mantenerse dentro del esquema de las cosas. Este esquema de las cosas, tal como está expresado en las creencias de todo pueblo, es su cosmología. Cualquiera que sea el término empleado, siempre forma parte del sistema religioso total de un pueblo una serie entera de instrumentos por medio de los cuales se moldean las fuerzas del universo con el fin de lograr los deseos humanos. Estos instrumentos, llamados ritos, se pueden agrupar bajo la palabra ceremonialismo (Herskovits, 1984:396). 
La cosmología está conformada por los mitos que, como lo expresa también Herskovitz, "[son] como la carta constitucional de las creencias y presta sentido a la conducta ritual que se deriva de sus consagraciones" (1984:396).

No obstante la opinión del padre Juan Jacobo Baegert, que expresaba que algunos de los aborígenes peninsulares no tenían religión, puede afirmarse que sí, aún cuando aquí no puedan incluirse los conceptos éticos que caracterizan a otras creencias. La existencia entre ellos de mitos, "chamanes", curanderos, rituales y ciertos tabúes propone un universo mágico anterior a la llegada de los misioneros. Baegert decía lo siguiente acerca de la barbarie de los californios: "Donde no hay autoridad suprema, ahí parece, no puede existir tampoco religión alguna, porque la religión exige que haya leyes y su aplicación" (1942:125). Sin embargo, no descarta el sobrenaturalismo:

Siempre ha habido entre ellos brujas y hechiceros y todavía los hay, pero en verdad, les falta mucho para que merezcan ese título. Hay evocadores y evocadoras del diablo, aunque nunca lo han visto; curanderos y curanderas de enfermedades que nunca curan; hacedores y hacedoras de pitahayas, aunque sólo son capaces de cogerlas y comerlas (Baegert, 1942:125).

\section{Y también prohibiciones:}

Había yo observado que algunos hombres, todavía bastante fuertes aunque peligrosamente enfermos, no querían dejarse conducir o llevar a la misión, donde hubieran recibido mejor trato para el cuerpo y el alma. Pedí explicaciones y se me dijo que significaría burlarse de los muertos, si se les enterrase con el repique de las campanas, con canciones u otros ritos cristianos católicos (Baegert, 1942:125).

Aunque Baegert no reporta el culto a dioses entre los guaicuras, las anteriores notas demuestran la práctica de la magia entre ellos; la aceptación de un orden sobrenatural y cierto temor a determinadas transgresiones, lo que implica su obediencia a una religión de acuerdo a la definición mínima que da Herskovits acerca de este concepto: "Creencia en, e identificación con, una fuerza y poder mayores” (Herskovits, 1984:413).

En las sociedades ágrafas, como las que existían en Baja California antes de la llegada de los misioneros, los mitos no eran transmitidos literalmente de generación en generación, sino solamente en sustancia. Esto significa que la esencia del mito era lo que predominaba en la memoria sin importar tanto los detalles del mismo, lo que implica la remodelación que pudieron haber sufrido como la aclara el mismo Baegert: 
No ignoro que alguien ha escrito que en California, por lo menos en una tribu, se encontró cierto conocimiento de la encarnación del hijo de Dios y hasta de la santísima trinidad, pero, sabiendo yo, que tales conocimientos de los misterios sólo pueden haberles sido enseñados por medio de la predicación del Evangelio, no me cabe la menor duda de que todo esto es un timo y una mentira de parte de los californios, en estos últimos años, ya han sido enseñados y bautizados, y que lo dijeron únicamente con el propósito del lisonjear a su misionero (Baegert, 1942:128).

Aunque muy diferente al conocimiento que se obtiene por medio de la observación y el análisis, la verdad mítica circunscribe una sapiencia comparable en su manera de ser asimilada a la comprensión del arte. Pero como éste, también se vuelve obsoleta y pierde validez según el observador y según el tiempo. Por esto, la ingenuidad de los mitos debe ser puesta entre paréntesis y no eliminar la posibilidad de un contenido profundo.

La verdad de un enunciado sólo puede comprobarse a partir de los fundamentos a los que debe su origen y por la vía por la que el hombre fue conducido a ella. El enunciado mítico acerca del origen de un fenómeno se basa en la "naturaleza particular del fenómeno mismo", y el camino de su formulación es la vivencia concreta y totalmente espontánea del hecho particular, que ve presente todavía, en el fenómeno mismo, la fuerza creadora que lo ha producido tal cual es. Así, por ejemplo, remonta la mortalidad de toda criatura viviente a un acontecimiento originario que en el fondo no hace más que circunscribir todas aquellas particularidades de los hechos reales que hacen que lo viviente no pueda aparecer de otro modo en la imaginación que como mortal. La verdad de la descripción de la realidad originaria descansa en el conocimiento verdadero de la esencia de la realidad viva, obtenido mediante una intuición directa (Jensen, 1986:83-84).

La semejanza de las estructuras de la fe cristiana con algunas narraciones cosmogónicas de los aborígenes peninsulares constituye una incógnita. El padre Miguel del Barco, más analítico que Baegert no se atrevió a cruzar esta frontera de conocimiento en la que todo comentario posterior hubiera sido simple especulación:

No hay memoria ni conservan tradición de que algún desgraciado extranjero halla vivido entre ellos y el cual pudiese haberles enseñado los misterios de nuestra santa fe, los cuales aquella gente hubiese desfigurado con el tiempo y mezclado necedades con ellos, como se inclina a sospechar nuestro autor. Y si no hay memoria de tal extranjero o extranjeros, ¿cómo se podrá averiguar 
que de ellos aprendieron los californios algunos de los dogmas que conservan, aunque gravemente alterados? Esto, por más que el autor lo desee, es imposible (Del Barco, 1973:215).

Clavijero, al igual que Del Barco, descarta esta posibilidad a la llegada de los misioneros jesuitas y también confiesa su perplejidad respecto a lo anterior:

No puede dejar de causar admiración el hailar en los dogmas de los bárbaros cristianos tantas señales, aunque desfiguradas, de las verdades cristianas. Podría sospecharse que fueron instruidos en ellas por algunos cristianos, porque en los cincuenta años que precedieron a la entrada de los jesuitas en la península, arribaron a ella muchas embarcaciones de México y de otras partes; pero ninguno permaneció allí el tiempo necesario para aprender alguna de aquellas difíciles lenguas, y los mismos californios, preguntados acerca del origen de su doctrina, afirmaban constantemente que la habían recibido de sus antepasados (Clavijero, 1970:72).

Entre las características generales de los mitos de la península de Baja California, sobresalen tres tipos de personajes: los espíritus humanos o héroes antropomorfos, los animales con características humanas buenas y malas, y los "monstruos".

En los mitos donde aparecen héroes humanos o espíritus, estos personajes son los creadores del cielo, del mar, de la tierra, del sexo masculino y femenino y de todo cuanto existe. Entre este tipo de mitos tenemos el pericú, el guaicura, el cochimí, el kiliwa, el kumiai y cucapá.

Por otro lado, hay mitos protagonizados por animales que poseían emociones, inteligencia y facultad de hablar. Por lo tanto, actuaban y vivían como humanos. Mitos como éstos son el cucapá y el kumiai.

\section{SOCIEDADES INDÍGENAS DE LA PENÍNSULA}

Se ha determinado que a la llegada de los españoles a la península de Baja California en 1534, existían cuatro grupos o unidades lingüísticas. En el extremo sur había sociedades que hablaban el idioma pericú y guaicura. Más al norte, extendiéndose a través del desierto Central, habitaban los hablantes del cochimí, y en la zona septentrional se desarrollaron los grupos de la familia lingüística yumana integrados al menos por las lenguas kiliwa, paipai, kumiai y cucapá. Los ancestros de estas comunidades habitaron en la región desde hace miles de años (Laylander, 1987:120) y tenían una cultura adaptada a la aridez de los desiertos peninsulares, al 
clima templado o frío de las montañas de San Pedro Martir y sierra de Juárez y a las temperaturas más constantes de las costas del Pacífico. Cada comunidad ocupaba determinados territorios donde vivían en un delicado equilibrio con su habitat. Cazaban, recolectaban y pescaban cientos de especies de animales y alimentos silvestres, siguiendo para ello un complejo circuito terrestre lleno, probablemente, de magia y misterio.

Con la llegada de los españoles se establecieron asentamientos misionales jesuitas en poco más de la mitad de la península que duraron casi 70 años (de 1697 a 1767), hasta que los misioneros tuvieron que irse por razones políticas. En los centros regionales jesuitas llegaron a reunirse cientos de nativos cochimíes, guaicuras y pericúes, ahí los jesuitas les ofrecían alimentos, les enseñaban algo de la religión católica y les inculcaban aspectos de la "cultura" occidental. Lamentablemente, estos indígenas fueron diezmados por enfermedades y circunstancias adversas como el rechazo de su cultura, religión y la imposición de trabajo excesivo.

Antes de la disolución de estas comunidades, los misioneros consignaron minuciosamente en sus diarios y otros documentos, un acopio de datos sobre su vida y creencias, lo cual incluye la información sobre sus mitos. Dicha información salió a la luz pública en libros como el de Venegas (1979) y de Clavijero (1970) o de Del Barco (1973) y de Baegert (1942).

Es evidente que los misioneros dominicos que se ocuparon de las misiones del norte casi no escribieron sobre los asuntos pertinentes a la cultura y creencias de los nativos de su región. La etapa de dominio dominica la sobrevivieron los nativos yumanos no sin antes sufrir considerables bajas por la exposición a enfermedades que no conocían. Posteriormente se confrontaron con pobladores de nacionalidad mexicana y en menor escala con extranjeros. Por eso, la mayoría de los relatos mitológicos de estas comunidades provienen de fuentes de finales del siglo pasado y sobre todo de la primera mitad de este, exceptuando algunos muy recientes, como los tempranos investigadores Peveril Meigs (1939 y 1971), Constance Dubois (1901, 1904, 1905a, 1905b y 1907), y Kelly (1977).

\section{MITOS DE ORÍGENES DE LAS SOCIEDADES SUREÑAS: COCHIMÍ, GUAICURA Y PERICÚ}

Acerca de la cosmogonía de los indígenas del centro y sur de la península se pueden establecer los siguientes parámetros: a) Los mitos tratan principalmente el tema de la creación del mundo; b) todos fueron consignados en fuentes documentales coloniales; $c$ ) en algunos casos los consignatorios, de los cuales la mayoría eran religiosos del cristianismo, interpretan el mito a partir de su cosmovisión; d) se presentan, en algunos 
casos, semejanzas entre los mitos y la fe católica; e) los personajes míticos principales toman la forma de espíritus y héroes antropomorfos.

Los misioneros jesuitas registraron en forma sintetizada el mito de la creación de cada núcleo lingüístico, interesados tal vez por conocer lo que ellos consideraban el culto de los naturales y denotando una formación religiosa en lugar de antropológica.

Lo subjetivo es evidente en las interpretaciones que hicieron al encontrarse ante un mundo diferente al suyo. Lo anterior lo podemos apreciar en un documento elaborado, se cree por Benno Ducrue, misionero jesuita de origen alemán, que hizo la siguiente descripción de una creencia mitológica de los cochimíes.

La creencia más general entre las tribus del norte era que el gran Dios o señor se encontraba en una constante guerra y persecusión con otro Dios de la vida o la vida misma. Esto se debía a que el Dios de la vida nació de una mujer que se había embarazado bajo la sombra de un árbol (Aschmann, 1966).

Ducrue interpreta esta creencia de la manera siguiente:

En esta creencia, quizá Satanás es transformado en ángel de la luz, y uno recuerda los misterios de la verdadera fe o sospecha que sus ancestros pudieron haber recibido indicaciones de la luz de las sagradas escrituras y de sus misterios. Sin embargo, sus descendientes permanecen en la profunda sombra del árbol. (Aschmann, 1966).

En este párrafo, Ducrue encuentra en su mundo el origen del pasaje mitológico que descubrió entre aborígenes cochimí. El origen, como lo manifestó, fue la luz de Las Sagradas Escrituras.

Esta descripción nos demuestra algo que es importante considerar cuando analizamos las descripciones de los mitos: el hecho de que hicieron un esfuerzo de comprender e interpretar sus observaciones, dentro de un marco comparativo: explicar lo desconocido en términos de lo conocido.

Los mitos de creación cochimí, pericú y guaicura coinciden en que hay una deidad fundamental creadora de todo lo que existe pero que, sin embargo, nunca tiene contacto directo con la humanidad (ellos son Menichipa, Niparaya y Gumango respectivamente) hasta que mandan a un representante o hijo suyo que se encarga de perfeccionar la obra de su antecesor y comunicar sus enseñanzas a los hombres.

Miguel Venegas, misionero jesuita, reportó tres mitos de creación, uno de los cochimíes, otro de los pericúes y otro de los guaicuras (1979:523-530). De los pericúes nos narra lo siguiente: 
Que en el cielo vive un Señor, a quien llaman Niparaya, el cual hizo la tierra y el mar, da la comida, creó los árboles y todo lo que vemos, y puede hacer cuanto quiere. No lo vemos, porque no tiene cuerpo como nosotros. Este tal Niparaya tiene mujer, llamada Anayicoyondi, y que aunque no usa de ella, por no tener cuerpo, ha tenido tres hijos, de éstos el uno es Qaayayp, que es hombre y lo parió Anayicoyondi en las sierras de Acaraqui, y otros dicen que en unos cerros colorados, que están camino de Santiago de las Coras y llaman los Cunimniici. El dicho Quaayayp estuvo entre éstos (indio del sur) y los enseñó. Era poderoso y tenía mucha gente porque se metía dentro de la tierra y sacaba gente. Enojáronse con él y lo mataron. Cuando lo mataron le pusieron una toquilla de espinas. Está hasta hoy muerto, pero muy hermoso, sin corrupción alguna, echando continuamente sangre, pero no habla por estar difunto, pero tiene un Tecolote o Búho que le habla.

\section{Añade que:}

en el cielo hay mucha gente, más que acá en la tierra y que antiguamente hubo allá unas grandes guerras, porque un gran personaje, a quien unos doctos llaman Wac, y otros Tuparan, se opuso al gran Señor Niparaya y con sus aliados y gente peleó contra él, pero al fin fue vencido por Niparaya, quien luego le quitó a Wac-Tuparan cuanto tenía, las muchas y buenas pitahayas y las demás comidas, lo echó del cielo a él y a su gente, los encerró dentro de una cueva en la tierra y para que no se salieran, creó las ballenas en el mar, las cuales espantan y atemorizan a Wac-Tuparan, para que no salga.

\section{Dice además,}

Que el gran señor Niparaya no quiere que la gente pelee, porque todos los que mueren flechados no van al cielo; por el contrario. Wac-Tuparan quiere que la gente pelee porque mueren flechados y van a donde él está. Hay dos bandos entre los indios: unos que siguen la parcialidad de Niparaya y éstos son gente grave y circunspecta y con facilidad se reducen a la razón explicándoles (valiéndose de sus mismos dogmas) las verdades cristianas. Otro bando es de los que siguen a Wac- Tuparan y éstos son del todo perversos, hechiceros y curanderos, de quienes hay enjambres. Estos mismos de la secta de Wac-Tuparan, tienen otros principios totalmente exóticos: como que las estrellas son metales relucientes, que la luna la creó Cucunumic; que las estrellas las hizo Purutabui y otras cosas de este modo.

La notable asimilación de elementos católicos sugiere que tal vez este mito fue registrado cuando la evangelización de los pericúes se encontraba 
en una etapa avanzada. También debemos tomar en cuenta las explicaciones mencionadas al principio de este ensayo y en las que Clavijero y Del Barco expresaron lo poco probable que era la predicación del cristianismo entre los aborígenes por hombres blancos anteriores a los misioneros jesuitas. Por otro lado, Miguel Venegas, el misionero jesuita que relató este mito en su obra denominada en un inicio Empresas apostólicas (1939) reorganizada y aumentada por andrés burruel en 1757 y denominada Noticias de la California, utilizó información recopilada por diferentes misioneros que trabajaron en la empresa evangelizadora en el territorio de Baja California. Venegas vivió y trabajó en la zona central de México y nunca visitó ni habitó en Baja California (Laylander, 1987:108-109). Lo que se deduce es que el mito debe haber sido registrado entre el establecimiento de la primer misión en 1697 y la reorganización de la obra de Venegas en 1757: ¿Acaso en tan sólo 60 años tuvo tal efecto el jesuita sobre los pericúes?

Por otro lado, el mito guaicura está posiblemente más apegado al mito de la creación narrado por éstos antes del contacto europeo ya que no se perciben rasgos evidentes de la religión católica.

Resulta interesante descubrir que también se mencionan las capas de cabellera humana y las tablas ceremoniales: elementos de considerable importancia en las ceremonias, no sólo de estos grupos, sino de todas las comunidades del centro y sur de la península. Hablaremos de estos rasgos después de analizar el mito según la versión de Miguel Venegas.

No tienen éstos en su lengua el vocablo que signifique propiamente el cielo, pero a éste le entendían con la palabra general notu, que significa arriba o alto. Dicen pues, que en el cielo, hacia la parte del norte, hay un espíritu principal que llaman Gumongo: éste envía las pestes y enfermedades, y en tiempos pasados envió a otro espíritu a que visitase la tierra, a quien llaman Guayiagui. Cuando éste vino, fue sembrando las tierras de pitahayas, fruta de la más abundante en la California y componiendo los esteros de la costa del Golfo, hasta llegar a una gran piedra en un estero muy capaz, cerca de Loreto, que hoy llaman los españoles Puerto Escondido, donde hizo su mansión por algún tiempo. Aquí otros espíritus inferiores que le servían, le traían pitahayas para comer, y peces que cogían en el estero. La ocupación de Guayiagui era hacer vestidos para sus sacerdotes, llamados en su lengua dicuinocho, formados de los cabellos que le ofrecían. Después de algún tiempo prosiguió Guayiagui su visita, sembrando pitahayas y componiendo esteros en la costa, por todo el territorio de la nación de Loreto, dejando pintada para la memoria una tabla de que usaban los dicuinochos, o sacerdotes en sus bailes y fiestas. Añadían estos doctores: que el sol, la luna y los luceros eran 
hombres y mujeres; que todas las noches caían al mar de poniente y se veían precisados a salir a nado por el oriente: que las otras estrellas eran lumbradas, que hacían en el cielo aquel espíritu visitador y su comitiva: que aunque se apagaban con el agua del mar, después las volvía a encender por el oriente.

Venegas describió a los shamanes del grupo de Loreto diciendo que se cubrían totalmente, desde la cabeza a los tobillos, con una capa elaborada de cabellera humana y que se adornaban la cabeza con plumas de halcón y con las plumas más grandes hacían abanicos que traían en la mano. Por otro lado, Juan Jacobo Baegert observó que tanto hombres como mujeres se cortaban el pelo cuando llevaban luto. De aquel pelo, los curanderos y hechiceros confeccionaban pelucas y trajes rituales. Con respecto al uso de estas cabelleras observemos lo que expuso Fray Luis Sales, misionero dominico que laboró en la misión de El Rosario con indígenas cochimí:

\begin{abstract}
El viejo forma de cabelleras de difuntos una como capa pluvial y los otros viejos más ancianos pintados de negro y con unas pieles grandes de venado a modo de capas atadas con cordeles se visten, y con unos palos largos en las manos, y en el remate de algunas cabezas de difuntos, muertos en sus guerras: habiendo paseado en circo con mucha formalidad, y sin hablar palabra, se queda el viejo en medio del circo, intima silencio a los circunstantes, y les habla sobre el fin de aquella función: les dice, que el capitán de todos los animales lo envía, o si le parece les asegura que él es Dios de todo, y lo dice con tal satisfacción, y lo oyen con tanto gusto, que causa admiración [....] les habla de las costumbres antiguas, envueltas con mil contradicciones, da razón de todas sus habilidades, curaciones, muertes y facultades y les asegura que tiene amistad con los difuntos y luego saca unas tablas....(Citado en: Álvarez, 1975:53).
\end{abstract}

El mito de la creación guaicura se refiere también a las tablas ceremoniales. La descripción de estos objetos fue hecha por el padre Segismundo Taraval, jesuita italiano que laboró principalmente entre los pericúes desde 1717 hasta 1734. Taraval mencionó haber observado entre los instrumentos de una hechicera pericú una tabla angista agujereada y cubierta de plumas (Álvarez, 1975:30).

Por otro lado, a través de una descripción hecha por Clavijero, podemos imaginarnos la posible función de estos instrumentos. Los guamas (shamanes), según él, enseñaban a algunos niños los secretos de su oficio, y al hacerlo les mostraban:

especialmente en hacer en ciertas tablitas algunas figuras misteriosas, que fingían ser copias de las que según decían, les había 
dejado al retirarse el espíritu visitador. Estas tablitas eran los libros en que fingían leer la naturaleza de las enfermedades, los remedios....las futuras mutaciones del aire y aún el destino de los hombres. (1970:73).

Consag, padre jesuita, reporta en 1746 que los indígenas al oeste de San Borja empleaban la tabla como una especie de altar colocándola al frente de sus ídolos menores. Las tablas ceremoniales como las capas de caballeras y los cetros adornados con plumas fueron objetos de parafernalia religiosa y en el caso particular de las tablas se observa que servían a los hechiceros o chamanes como fuente de poder "para llevar a cabo sus adivinaciones y curaciones" (Álvarez, 1975:30).

Los cochimíes, como el resto de los indígenas bajacalifornianos, tenían su religión o mejor dicho, su cosmogonía. Creían, según el padre Miguel Del Barco, en la inmortalidad del alma. Sobre esto nos dice:

Los cochimíes decían que los buenos, cuando mueren van hacia la parte del norte, que suponían tierra mejor y más abundante de sus comidas; y que los malos iban hacia la parte del sur que, en su aprensión, era tierra más desdichada. (Del Barco, 1973:217).

Con respecto a esto mismo celebraban al parecer, como es el caso de otras comunidades de Baja California, una fiesta de conmemoración a los muertos.

Fingían que éstos residían en los países septentrionales, venían cada año a hacerles una visita. Conviviéndose los hombres en el día de la visita, obligaban a las mujeres aun amenazándolas con enfermedades, a que buscasen en el bosque y en el campo una gran cantidad de víveres para regalar a los difuntos. El día señalado para el aniversario, los hombres reunidos en un emparrado comían toda aquella provisión, mientras las mujeres y los niños, distantes de aquel lugar, lloraban abundantemente la muerte de sus parientes, para aquél para cuya comida se habían fatigado tanto. Los hombres cuidaban tanto de que aquel misterio estuviese oculto a las mujeres, que un joven por haberle revelado a su madre, fue muerto inmediatamente por su mismo padre (Clavijero, 1970:72).

Los cochimíes celebraban también una fiesta que se llamaba del hombre venido del cielo en la que comían y bailaban y al igual que la ceremonia anterior, encargaban los frutos a las mujeres. Explica Clavijero lo siguiente sobre esta ceremonia:

Llegando el día señalado para la fiesta, escogían a un joven que debía representar al personaje de aquel numen, y le vestían secre- 
tamente de pieles después de haberle pintado con varios colores para que no fuese conocido.

Éste se escondía en algún monte cercano al emparrado, en el cual entraban los hombres a esperarle, quedándose lejos las mujeres y los niños, aunque a vista del emparrado y del monte. El joven disfrazado, cuando llegaba la hora de dejarse ver, aparecía en la cima del monte y desde allí descendía corriendo velocísimamente hasta el emparrado, en el cual era recibido con mucho júbilo (Clavijero, 1970:72).

A este numen, según Clavijero, le llamaban tama amabai tevivichi, o sea, el hombre venido del cielo.

La siguiente es la transcripción del mito de la creación cochimí, registrado por el padre dominico Luis Sales que laboró en las misiones de El Rosario, San Vicente y San Miguel entre 1772 ó 1773 y 1790 (Laylander, 1987:122).

Dicen pues que un capitán grande (así se explican cuando quieren expresar el carácter, y ponderar las circunstancias de un sujeto) hizo el cielo, la tierra y cuanto existe en ellos. Este capitán se llamaba menichipa (hablando según el idioma y tradición del pueblo Viñatacot o misión de nuestra Señora del Rosario); que luego crió otro semejante a sí mismo y se llamabaTogomag que después hizo a un hombre y a una mujer; que éstos tuvieron un hijo llamado Emai-cuano; a éste lo prohijó el capitán grande, y le dio todo su poder, y todas las cosas y facultades se las puso en sus manos; a este hijo pertenecía el cuidado de los casados, y éste es el que distribuyó los casamientos de los hombres con las mujeres: Menichipa, aunque había creado todas las cosas, las dejó muy imperfectas; pero el prohijado las perfeccionó, endulzó las semillas que eran amargas, y amansó los animales que eran feroces: para que las gentes no tuvieran tanto frío colocó fuego debajo de la tierra y quejándose los hombres de que el calor era mucho escupió sobre la tierra, y su saliva se convirtió en mares, ríos, fuentes y lagunas; enojados los hombres de ver tantas aguas lo quisieron perseguir, y entonces empezó a llorar y sus lágrimas formaron lluvias; después puso nombre a todas las cosas, les enseñó el modo de la generación, pues la primera multitud de gentes la fue fabricando con su propia mano, y fatigado, enseñó a los hombres a procrear, mandó celebrar bailes y fiestas, y los puso a hacer exequias a los difuntos que hubiesen muerto con la muerte natural; que los de muerte violenta los quemasen; los que fuesen más valientes muriendo irfan debajo del norte, donde estarían todos los fundadores, y allí comerían venados, ratones, conejos y liebres. Mandó que las mujeres estuvieran sujetas a los hombres, y que entre éstos 
hubieran algunos que fuesen creados sin réplica. Añaden que Meñichipa fue herido por los hombres, $\mathrm{y}$ haciéndose el muerto se levantó: pero que los malhechores huyeron, y hasta ahora no se sabe dónde están. Habiéndoles yo preguntado, que dónde estuvo Menichipa antes de crear las cosas, respondieron que debajo del norte hay una bola de tierra que se crió repentinamente con Meichipa: que allí vivía muy triste, porque no tenía compañeros: y de aquí se movió a criarlo todo. Concluyen que Menichipa crió mucha gente soberbia y mala y queriendo que todos estuvieran en paz, los desterró del mundo, y los encerró debajo de la tierra; sin embargo permite que de cuando en cuando salgan a engañar a los hombres: a esta gente soberbia que en unos parajes llaman Chillinchs, en otros Tevigol en otros Chilay, que equivale a Demonio: éste anda visiblemente entre ellos en muchos parajes apoyando sus maldades; en otros se les aparece de noche revestido de fuego, y les amenaza; y poseídos de este terror practican cuantas maldades les inspira: pero los ya cristianos se defienden ya conel santo Rosario, como lo puedo atestiguar en unos indios de Viñatacot (Álvarez, 1975:40-41).

\section{MITOS DE ORÍGENES DE LAS SOCIEDADES NORTEÑAS}

Como se explicó anteriormente, en el norte habitaron, por lo menos durante la prehistoria reciente, sociedades que hablaban lenguas de la familia lingüística yumana y de las cuales hoy perviven cuatro comunidades: los kumiai, los kiliwa, los cucapá y los paipai. Se ha visto que hasta el momento no se ha conocido ningún documento misional, como los de los jesuitas, que haga mención de sus creencias míticas; sin embargo, investigadores de fines del siglo pasado y principios de este han hecho grandes contribuciones a este conocimiento. A continuación presentamos los mitos que, como se verá, difieren marcadamente de las comunidades del sur.

Dentro del ciclo de la mitología cucapá, kiliwa y kumiai en lo que se refería a la cosmogonía encontramos dos etapas:

Primero, la aparición de el o los dioses sobre la superficie del mundo; quienes ya se encontraban como potencia o semilla dentro del seno de la tierra o bajo el mar. Luego, el periodo de creación de las entidades que se ven en el cielo y en la tierra para a continuación repartir a la humanidad, sus linajes, sus bienes y sus tierras sobre los cuatro puntos cardinales.

Es notable también la relación más intensa que se manifiesta del hombre con los animales, como es el caso del coyote. Pero analicemos primero los pasajes míticos de los grupos yumanos mencionados y posteriormente los comentaremos. 


\section{Kumiai}

Al principio no había tierra, sólo agua por todos lados, pero bajo el agua había una cueva en la que vivían dos hermanos. El mayor tenía un tejón, y el menor una avecilla. Ambos habían estado allí durante larguísimo tiempo jdesde siempre! parece. Un día el mayor dijo al hermano menor: "debemos subir hasta la superficie, y ver lo que hay arriba". "Está bien", contestó el interpelado "yo voy primero", añadió el hermano mayor y diciendo así salió de la cueva con su tejón y nadó hacia la superficie llevando los ojos cerrados para que el agua salada no se los lastimara. Cuando llegó arriba, abrió los ojos y vio que todo era negro. Un poco después, el hermano menor le gritó desde abajo: "¿cómo se ve allá?" "Ven a ver" "¿cómo subo?" "con los ojos abiertos, para que puedas ver donde estoy". Repuso el hermano mayor maliciosamente, porque lo que quería era que el joven se dañara la vista para quedarél como el más fuerte y el de mayores bienes. Porque mintió él, mienten los seres humanos: es el principio de la falta de honradez en la humanidad. Cuando el hermano menor subió a la superficie llevando su avecilla, se había quedado ciego, porque llevó abiertos los ojos. Después de estar un rato en la superficie de las aguas el hermano mayor cambió su tejón por la avecilla del otro y le dijo que era hora de regresar a su cueva. El joven palpó la gruesa pelambre del tejón y dijo: "Hermano: este no es mi animal, el mío tiene suave la piel" "sí es el tuyo" repuso el interpelado, con lo que el joven lleno de ira volvió a la cueva.

Desde entonces, cuando el hermano menor está inquieto y se agita, tiembla la tierra. Él causa los temblores. No tiene nombre, pero el hermano mayor, quien creó todo, se llama Tcipakomat. Este formó primero la tierra ordenando a las hormigas que hicieran un montículo como los que todavía hacen en la actualidad, y los insectos fueron amontonando el barro que extraían del fondo del mar hasta formar un montículo que sobresalía de las aguas. Este fue el monte Wikami situado en las tierras de los Mojaves, al oeste del río Colorado, y aquélla fue la primera tierra.

Luego Tcipakomat hizo luz, para lo cual cogió un puñado de tierra amarilla, la comprimió hasta hacer una pelota y la tiró al cielo donde se quedó, convirtiéndose en la luna. Pero aquella luz era muy pálida así que Tcipakomat buscó tierra roja e hizo otra pelota que lanzó nuevamente al cielo y así formó el sol, que daba suficiente luz. Después formó todos los animales, luego con tierra, formó al ser humano. Al principio todos los hombres hablaron el mismo idioma. Entonces Tcipakomat cayó enfermo y nadie lo podía curar, pero los animales lo cuidaban, un animal distinto cada mes. Después de una larga enfermedad murió Tcipakomat y su cadáver fue 
incinerado para que el coyote no se lo comiera. Aquella fue la primera cremación, y fue hecha en el lado este del río Colorado. Mosca Azul (maskumpu'tai) encendió el fuego.

Durante el acto, gentes y animales se colocaron en círculos alrededor del cadáver, pero el coyote saltó sobre ellos, salvó del fuego el corazón de Tcipakomat y huyó con él hacia el este. En todo el camino, donde fue cayendo sangre del corazón, dejó manchas rojas en las piedras.

Poco tiempo después, la gente que entonces no sabía hacer mucho, decidió hacer algo. No tenía mucho en qué ocuparse en aquellos tiempos; no tenía cantos, ni danzas. Por fin decidieron hacer un "wokeruk" para Tcipakomat, pero no tenían idea de cómo hacerlo. Alguien sugirió mandar un mensajero al sur, hasta el mar donde vivía el monstruo Maijiyowita para pedirle ayuda. Maijiyowita lo sabía todo, y cuando la gente aprendió, aprendió en él. Enviaron al mensajero, quien se fue por el río en una burbuja de agua y así llegó a Halkwitat, donde las montañas lindaban con el río, al norte de Yuma. Halkwitat era como profundo hoyo con una corriente de agua interior. El hombre de la burbuja cayó al hoyo y se encontró de pronto en el estómago de Halkwitat. Entonces avanzó hacia el norte y consiguió una afilada piedra azul con la que abrió el estómago del mostruo y pudo seguir su camino al sur, al hogar de Maikiyowita, al que al fin llegó y le pidió que viniera a Wikami a enseñar a la gente cómo hacer cosas. Majiyowita prometió y el mensajero volvió al norte volando por los aires. Maijiyowita era alargado, parecía ciempiés. Salió de la margen occidental del río, y donde le iba arrastrando la cola, dejaba un rastro de rayas blancas que todavía pueden verse ahí.

Cuando llegó a Wikami, la gente había construido una ramada para el wakeruk, Maijiyowita llegó bajo la ramada y se enrolló para descansar.

Entonces algún tonto arrojó un palo ardiendo al techo de la ramada y ésta se incendio, como Maijiyowita bajo ella. Al ir consumiendo el fuego a Maijiyowita, el cuerpo se le fue desintegrando en pedazos que saltaban como chispa y caían sobre la gente, y ésta empezó a hablar distintos idiomas según los trozos ardientes que les cayeron encima. La cabeza de Maijiyowita se fue rodando hasta el río y formó una isla que todavía se halla en aquel sitio.

Después de estos acontecimientos, los grupos que hablaban distintos idiomas salieron de Wikami. Los más ancianos salieron primero al sur y luego al este, y se quedaron con todos los bienes porque llorando a lágrimas vivas se los pidieron a los demás y éstos se los regalaron. Por eso es que los otros indios son tan pobres.

Cuando la gente llegó a Yecakokolpa, un círculo de piedras que se halla al sur de Needles, California, todos se vieron obligados a 
dar vueltas, corriendo sin respirar, alrededor del círculo, y la única que pudo hacerlo fue el águila. (Mito Kumiai anotado por Malcom Rogers en: Álvarez, 1975:62-64).

\section{Cucapá}

Sipa y Komat, los dioses creadores, estaban bajo el agua y la tierra, viviendo de la forma en la que vive un niño en su madre. Toda la tierra estaba cubierta de agua. Empezaron a hablar de salir a la superficie. Komat fumó un cigarro para hacerse de fuerza adicional y porque él era el mayor empujó hacia afuera a Sipa. Cuando llegaron al exterior Komat se tornó el más joven y Sipa el mayor, porque Sipa salió primero. Estos dos creadores eran primos (Kawak). Cuando subían por el agua, Komat le preguntó a su hermano que cómo le había hecho y Sipa le contestó que abrió sus ojos. Cuando el hermano mayor abrió los ojos en el agua fue cegado. No había tierra, de manera que hicieron que las hormigas voladoras, pequeñas hormigas rojas y hormigas rojas grandotas, excavaran cerros de tierra para empujar al mar y para proveer tierra ya que la tierra se secó en algunos lugares, Sipa y Komat empezaron a hacer hombres. Ambos hicieron todo tipo: indígenas, mexicanos, chinos, americanos. Mientras trabajaban, se preguntaban qué tipo estaban haciendo; si era un cucapá, la respuesta era cucapá y luego el nombre del linaje.

Komat el gemelo ciego, después de un rato tuvo que orinar, así es de que se levantó y caminó hacia algunos matorrales. Mientras no estaba, Sipa cambió a la gente que había hecho por los de Komat, porque eran mejores. Cuando retornó Komat tentó a los hombres y supo que no los había hecho. No dijo nada y continuó haciendo más. Luego fue a los matorrales otra vez a orinar y mientras que no estaba Sipa le cambió su zorra por la de Komat, cuando regresó Komat, él supo que los animales habían sido cambiados porque podía escuchar a la zorra golpeando su cola en el piso. También podía discernir la diferencia en la piel del animal que él tenía, Komat entonces llamó a su zorra por su nombre: "cemwa mesir". Cuando su zorra escuchó esto (aunque Komat habló muy despacito), rasguñó y trató de escaparse. Komat continuó trabajando en sus hombres todo este tiempo.

Una vez que ya habían hecho todos los hombres, estaban listos para tener ojos. Sipa sugirió que los pusieran en cada uno de los diez dedos de los pies. Komat dijo que esto no se podía hacer porque los lastimarían, y que los hombres no podrían ver cuando caminaban bajo el agua o en el lodo o el polvo. Dijo que el mejor lugar para los ojos era la cabeza. Sipa finalmente estuvo de acuerdo, de manera que ahora todos los hombres 
tienen dos ojos en sus cabezas; bastante por encima del piso, y si uno es lastimado el otro puede ser utilizado.

Sipa elaboró un arco y una flecha, y cuando terminó esto, disparó la flecha en el aire y cayó y le pegó a Komat. Komat le preguntó el por qué había disparado la flecha de esa manera, y le explicó que sólo debía usar el arco y la flecha para matar animales. Komat estaba sentado en ese momento y la flecha le llegó por atrás y le pegó en la espalda. La herida no fue seria.

Todo era oscuro, de manera que Sipa intentó hacer un sol. Hizo uno muy pequeño, y la luz no era mejor que la de la luna. No le gustó a Komat, de manera que empezó a hacer un sol en etapas fáciles. Cuando hubiese terminado, aventó el sol hacia el este y después de eso éste viajó de este a oeste para que la gente supiera cuándo levantarse, cuándo trabajar, y cuando dormirse. Sipa iba a tirar su sol, pero Komat le dijo: "No, deja que se quede, será la luna". La gente puede distinguir las temporadas, los meses, y los días por la luna.

Cuando había terminado estas cosas, Sipa cambió su gente por aquellos hechos por Komat. Cuando Komat descubrió esa sustitución, estaba muy enojado esta vez. Se estiró y rompió los cielos y luego se bajó y se metió a la tierra, dejando un hoyo. Sipa se estiró y detuvo los cielos y brincó el hoyo con sus pies porque el humo, el aire, la electricidad, y otras cosas que causan la muerte salían de éste. Algo de esto escapó a la tierra a través de los dedos de Sipa.

Las siguientes enfermedades fueron introducidas en ese momento: im-konu, i: los huesos duelen y se hinchan; Comamuwa, ar: una llaga incurable en torso; KoRop pousa: un dolor en el costado causado por un objeto intrusivo; ao.ax o ao si.rk: rabadilla de niño; KoRop xwot: dolor en todo el cuerpo, curado al atraer sangre; hi.akwir: dolor de estómago, excremento blanco con líneas de sangre, o puede ser verde, el paciente no puede comer; smalus ptei: enfermedad de la piel con llagas, una viruela "grandota" smalus ramnos: viruela; mikspauk: algo parecido a la viruela pero el paciente se recupera rápidamente; niyel sakwas: paperas; kapiuhal: ojos lastimados.

Cuando el sol fue reparado y el suelo cubierto, Sipa se sentó e hizo más gente. Luego empezó a separarlos. Los puso en una fila y repitió el nombre de cada tribu de cada uno: Koapa'. kwa al. kwa/alwa, yikwele'o hamasul, kakwal, kwinyahes, kamya'. hkwas. kowi, kahwe, hlkhlak, li'pa kw/al. mitsha, kwisan, humha.p, yaupai hwa.t, semowau, htpanyia', khwan, hatpas.ma', hatpas.

El lugar donde estos gemelos salieron del mar, y el lugar donde estas personas fueron creadas y donde Komat se volvió a meter debajo de la tierra se llama wa kunyuR (casa desnudada). 
Después de que Komat se metió en la tierra. Sipa hizo más gente y quería decirles cómo hablar y cómo vivir, así es que construyó una casa para colocarla ahí. Esta casa fue hecha de ladrillos de adobe y posteriormente fue convertida en piedra de manera que ahora está desnudada. Está en una montaña 30 millas al este de Tucson [esto parece demasiado lejos del territorio Cucapá]. Los maricopa saben donde está este lugar.

Cerca de la casa, en wa kunyuR, habían dos caballos y jinetes: un hombre cucapá en un caballo blanco y un yuma en un caballonegro y las huellas todavía se pueden ver.

Mientras estaban en esa casa los niños aprendieron a jugar. Un juego se llamaba Skook. Este es un juego que se juega empujando con los pies. Los niños yuma y cucapá juegan esto: no se enojan, sólo juegan. Todas las tribus jugaban este juego juntos. El niño yuma empujó al niño cucapá y él empezó a llorar. El niño maricopa vino y se fue contra el niño yuma. El yuma le dio duro al maricopa también. Afuera de la casa había un poste como orquesta con un palo cruzando. Había 16 gallinas colgando, 8 en cada extremo. Sipa le pidió a los niños de cada tribu que le dieran vuelta al palo. Ninguno lo pudo hacer. Luego le pidió al niño cucapá y éste le dio vueltas al palo. Ésta era una señal de que siempre sería un buen trabajador.

Otro juego que jugaban era yo hwap. Este es un juego en el cual los niños se dividen y se avientan terrones. De un lado estaban los cucapá, pima y maricopa. En el otro lado estaban los yuma, mojave, yawapai, diegueño y kamia. Los paipai y los kiliwa eran demasiado chicos para este juego. Los yumas empezaron a tirarle a los cucapá y los hicieron correr y llorar; luego los maricopa llegaron a su rescate, y les dieron una paliza a los yuma y a los mojave. También aprendieron juegos para adultos pero no los jugaban. Mientras que la gente aún estaba en wa kunyuR. Sipa trajo dinero, oro, caballos, vacas y otras cosas y las dividió entre toda la gente. Los mexicanos y los americanos eran los más jóvenes y lloraban mucho, pidiendo todo, que el niño cucapá finalmente dijo: "Dáselo todo a ellos y cállalos".

Sipa entonces repartió los linajes. Esto lo hizo durante varios días hasta que algunas de las personas se cansaron de esperar, finalmente se enojaron, y dijeron que podían pasárselas sin linaje. Un hombre que vive en Baja California no tiene linaje y ningún nombre para sus hijas por este hecho. En yuma existe otro hombre que no tiene linaje. Las mujeres de su familia son llamadas skus, pero este nombre no les pertenece ya que no tienen linaje.

Sipa empezó a darles otras cosas a los indios. Les dio a los cucapá arcos y flechas, dos tipos de redes para la pesca, jarrones de cerámica, ropa y todas las cosas que utilizaban en los viejos días. Le dio a los diegueño estas cosas, pero también les dio cosas a los 
cucapá, cosas que no tenían: el miskwa' imagen para la ceremonia del kerauk (ceremonia de conmemoración de los muertos) la sonaja de venado, miel hervida que utilizaban las mujeres para pintar rayas en sus caras durante la ceremonia de conmemoración de los muertos, tabaco, cigarros de carrizo, una red para atrapar conejos, y un palo de cacería.

Cuando esto hubiese terminado Sipa llevó a la gente a la montaña sagrada en el territorio Mojave llamado wi kami. En wi kami, Sipa construyó una gran casa. Todos entraron a esta casa y empezaron a jugar juegos, cantando y divirtiéndose. Tenían suficiente edad para hablar. Sipa se estiró en la puerta para observarlos. (Información obtenida por William Kelly de el cucapá Sam Spa en la década de 1940. Traducido de: Kelly, 1977:115-117).

\section{Paipai}

En cuanto a los orígenes, Benito Peralta, de la comunidad de Santa Catarina, narra lo siguiente:

Cruzaron a esta tierra, al desemboque (del Colorado) al aguaje detrás del cerro (que le dicen). Allí se puso a cantar (Dios) acomodando las razas en sus hogares. "Aguaje de la hiedra" dice, llegaron (allá) estuvo cantando así. Estas tierras todas las emparejó. Estuvo nombrando las otras razas (apellidos). "los sureños, los norteños" dijo, la raza "cuervo" dijo, "juach" dijo, los "cuero colorado" dijo, los "jamsulch" dijo, los "kiliwa" dijo, los "bocas crudas" dijo. Estuvo nombrando los apellidos de cada pueblo, en su aguaje. Estuvo nombrando las tierras, los aguajes (de cada raza en) su casa, (en) su casa, (en) su tierra. (Este) es tu cerro. A todos les dijo: "Este será tu cerro, ésta será tu agua" dijo. Este tu camino, yo estoy diciendo a cada pueblo. Se fue, durmió, al día siguiente llegó. ¡No! dijo, ya (hay) pueblo allá, es de tal raza. Estuvo nombrando, en cada aguaje. Los del Aguajito (actual colonia Lazaro Cárdenas del valle de la Trinidad). Los de cuervo al calor del sol los de "la mancha de carrizo", los de "palo arrojadizo", los de "jamau". Nombró la tierra, y nombró razas, los "del cielo", los "cucapá", los "yuma", "los cualjmchaja", los "mojave", los "chljwa", los "tambo" nombró todos los apellidos. (Mixco, 1977:216-217).

\section{Kiliwa}

Metipa, el creador, salió de debajo de la tierra en un paso. Surgió de debajo de la tierra detrás de una pequeña montaña roja, Wey cojan, "cerro bueno". La montaña está hacia el desierto, para el otro lado de un bajío que está un poco más allá del paso de San 
Matías. Metipa primero hizo a sus cuatro hijos: Meniuikunama'. jialkaua'iapai (v), Joa'junama', y Upakunama'. Luego Metipa hizo la luna. La puso en el este. Menuikunama' pensó que estaba mal colgado, así es que se la llevó por el cielo y la colgó en el oeste. Así es de que la luna siempre se pone en el oeste. Luego Metipa quería hacer el sol. Lo tenía en su estómago. Se lo sacó por la boca y lo puso en el cielo: pero estaba algo mal, de manera que se lo volvió a tragar otra vez. Luego intentó sacárselo vía sus genitales, pero no pudo, y lo volvió a colocar en su estómago. Luego trató de sacarlo por el recto, y lo logró, colgándolo en el cielo en el este. Por este motivo la gente tiene rectos quemados. Luego empezó a hacer plantas, cerros y animales. Después de que todo estaba creado. Metipa nombró todo: antílopes, borregos cimarrones, conejos y todo. Luego hizo los cuatro mares. Todo era pequeño; cuando Metipa salió de la tierra sólo había un pedacito de tierra en donde se pudo sentar, y todo tenía que crecer, así como una persona crece. Luego hizo que todo creciera un poco más. Después de morir y de ser cremado, hizo una polilla (a'aukupojum), el tipo que los mexicanos llaman cigarrón. Este fue el último animal que hizo. Había olvidado hacerlo antes, y lo hizo entonces, cuando se acordó. Cuando Metipa murió volvió a meterse a la tierra, y sus huesos blancos se volvieron venas en las montañas, donde pueden ser vistos ahora.

Metipa había enseñado a sus cuatro hijos cómo hacer cosas: arcos, flechas, puntas de flechas, fuego, redes de mezcal, ollas, casas, cobijas y así, fueron los primeros en hacerlos. Metipa ordenó a sus hijos hacer estas cosas para la gente y casarse con mujeres y tener hijos. (Traducción del relato de José Espinoza en: Meigs. 1939:66-67).

Sipa y Komat, Mijiyowita, Tcipakomat y Metipa son las deidades que se mencionan en los mitos anteriores. No obstante que los kumiai y los cucapá admiten que son divinidades primarias, una de ellas es la principal y la que asume posteriormente la responsabilidad de la dirección final del mundo. Así en el mito cucapá de la creación, Komat crea hombres y da origen al sol pero no es él quien al desenvolverse más este génesis será el guardián de los primeros pasos de la humanidad sobre la tierra.

Es interesante ver que algunos grupos dan explicaciones similares a fenómenos que consideran irregulares como es el caso de los kumiai al referirse a los terremotos y la mentira en los hombres; o el inicio de las enfermedades según los cucapá. Ambos los consideran como consecuencia de las luchas de poder que tuvieron las dos divinidades originales. No existen pues, los áridos razonamientos acerca del mal que encontramos en otras mitologías. Sus luchas no se centran en el mando que tienen sobre determinado grupo de gente, sino sobre las posesiones: un tejón y una 
avecilla, o dos zorros, o los hombres de barro que elaboran. Sin embargo, no son luchas por el poder propiamente ya que Komat, el cucapá, o en el caso kumiai, el hermano de Tcipakomat no tienen casi tiempo de defenderse y son desposeídos de sus bienes casi sin que se den cuenta. Sipa o Tcipakomat son en este caso más una fuerza que un espíritu que se encarga de poner en orden el mundo. Sin embargo, una vez conjurado el caos con la vuelta de Komat a las entrañas de la tierra Sipa empieza con su misión de darle una finalidad y un sentido a lo creado, para lo cual distribuye a los hombres sobre la tierra a la vez que le da un nombre a cada tribu. No obstante, que Komat no era un ser carente de inteligencia o habilidad, sino por el contrario, aventajaba a Sipa en ciertas características como la destreza para crear hombres impecables; Sipa lo venció por su vitalidad (o Tcipakumat en el caso kumiai). Ni Sipa es la inteligencia ni Komat es la fuerza. De acuerdo con el relato cucapá muchas cosas fueron creadas según las instrucciones de Komat y Sipa solamente las permitió. Pero el primer golpe de inteligencia mañosa lo dio Sipa y con esto le creó una grave desventaja a Komat (su ceguera). Analizando bien el mito, Komat era más fuerte y tenía más habilidades y conocimientos que Sipa, sin embargo, éste venció por su fuerza de voluntad para sacar partido de las pequeñas ventajas.

El mito kiliwa es menos filosófico pero más aproximado al concepto monoteista del cristianismo. Su idea de la creación es semejante al del arreglo de una casa en la que todo debe ser puesto en un cierto orden: el sol, la luna, los animales, el mar. Incluso, Menuicunama, uno de sus hijos, interviene con su opinión en cuanto al lugar donde debe estar la luna.

La característica más original del mito kiliwa es la conexión que establece entre el hombre y el sol, ya que este cuerpo celeste lo señalan como salido del estómago del Metipa. Es escatológico, fuera de este contexto, ocuparse del recto como algo más que un conducto fisiológico, pero aquí podemos ver la diferencia entre el tabú de las sociedades ágrafas y la censura de las sociedades más desarrolladas. En ambos casos se soslayan los temas.

Tanto el mito cochimí como el mito kiliwa coinciden en que la divinidad creadora salió del interior de la tierra y en que las cosas no fueron perfectas en el momento en que fueron hechas, por lo que tuvieron que sufrir un cambio de lugar o un perfeccionamiento en sus cualidades. Sin embargo, el mito kiliwa de creación no contiene, como el cochimí, los conceptos de cielo e infierno y que también se observan en la cosmogonía pericú. Al parecer, el periodo de las misiones que duró más de un siglo en la península no fue una influencia definitiva en estos mitos de las comunidades establecidas al sur de la península sino que es más posible la 
difusión de estos elementos cristianos debido a los primeros exploradores y visitantes europeos que llegaron a las proximidades de Cabo San Lucas en los siglos XVI y XVII.

Por otra parte, otro rasgo sobresaliente en los mitos kumiai, cucapá y paipai es la presencia del coyote con características humanas y a quien los seres con quienes tiene cierto trato ven como el ladrón, el infractor, el indeseable, el tramposo, aquél a quien el sexo femenino ve con cierta simpatía pero no toman en serio. Aunque no se incluyen en este trabajo esto se observa también en el cuento paipai llamado "Las hijas del Tecolote"(Mixco, 1985:28) y el relato cucapá que se denomina "El Coyote y las muchachas rana" (Kelly, 1977:19).

El mito cosmogónico presentado en este trabajo solamente incluye el episodio relativo a la creación del hombre. Uno de ellos que no se transcribe en este trabajo y en el cual se relata que a causa del coyote muere Sipa y es otro coyote quien roba su corazón todavía intacto mientras el resto del cuerpo empieza a incinerarse. Probablemente el robo del corazón se relaciona, como en otras culturas, con el deseo del coyote de adquirir la fuerza y las cualidades de Sipa.

En el mismo mito de la cosmogonía cucapá y en un episodio denominado por Kelley (1976:119) "El coyote y las muchachas rana" encontramos el maleficio como parte integrante de su desarrollo. Intervinieron en su causa las mujeres, aunque éstas adopten la forma de un animal como en el caso de las muchachas ranas que vengan la muerte del coyote produciéndole una enfermedad incurable a Sipa el creador o como en el caso de la muchacha que viene de la luna y viola sexualmente a Spat Kwamai el joven que se convierte en águila y posteriormente en canibal. Este relato a través de las imágenes de la luna, el águila, la ballena y el mar parece mostrarnos ocultos simbolismos donde fuerzas como las del satélite y la gran masa de agua salada, activas e inertes a la vez, libraron una gran batalla para apoderarse del mundo. De esto solamente quedó como testimonio cerro Prieto y los cercanos "Volcanes de Lodo".

Es más evidente la influencia de elementos cristianos en los mitos pertenecientes a los grupos indígenas del sur de la península que en los de aquéllos que están cercanos a la frontera con Estados Unidos. Características tales como la creación de la luz, cielo e infierno, mesías redentor, padre creador, noción de pecado y separación entre fieles e infieles están presentes en las cosmogonías pericú y cochimí, mientras que en el mito de la creación de los kumiai solamente encontramos el elemento bíblico de la lengua original común a todos los hombres.

Aunque el proceso de aculturación posterior a las misiones se encargó de mermar la rica corriente de mitos y relatos que fluían a través de la 
tradición oral y en la que los jóvenes tomaban parte importante porque eran los encargados de aprenderlos y posteriormente transmitirlos, aquel árbol de narraciones autóctonas fue cercenado en muchas de sus ramas por las nuevas abstracciones y formas de pensar procedentes del viejo mundo.

A continuación se expone un relato breve en donde se muestra la fusión de las dos formas de pensamiento. Proviene de Benito Peralta de la comunidad de Santa Catarina:

Me han contado a mí mis antepasados que mucho más antes, en aquellos tiempos... andaba un hombre muy poderoso, muy poderoso, y no lo querían, lo maltrataban mucho, lo mataban, lo tiraban ahí pa'l monte y al rato ya andaba, lo hacían pedazos camaradas y al rato ya andaba. Entonces acá pienso que ha de ser Jesús Cristo, hasta que subió al cielo, pero no subió en la cruz clavado, sino cuerpo y alma se elevó; pero va [a] volver, pero no dicen cuándo. Por eso es que nosotros creemos que hay un solo Dios, un solo ser supremo que domina todo el mundo. Que hizo todas las cosas del mundo.

Luego reflexiona Benito...

Por eso es que [a] cualesquier religión que viene a esta comunidad nosotros la recibimos bien. Si viene la católica la recibimos, si viene otra religión también, ¿por qué?, porque nosotros queremos a un solo Dios y aquellas personas que vienen "tan hablando de Dios" (Bendímez, 1989:28).

No obstante, las bases de la cosmogonía de los antiguos californios no son imposibles de conocer; ya que aún quedan los mitos y relatos mencionados anteriormente y que conservan la esencia de un universo prístino.

\section{BIBLIOGRAFÍA}

ÁLVAREZ de Williams, Anita. 1975. "Primeros pobladores de Baja California". Talleres litográficos del gobierno del Estado.

BAEGERT, Juan Jacobo. 1942. Noticias de la península americana de California. Edición José Porrúa e Hijos.

BENDÍMEZ, Mary Julita. 1989. "Historia oral: Benito Peralta de Santa Catarina, comunidad paipai". Cuadernos de Ciencias Sociales. Serie 4, no. 4. IIS-UABC.

CLAVIJERO, Francisco Javier. 1970. Historia de la antigua o Baja

California. Imprenta de Juan R. Navarro, Editor México. 
DEL BARCO, Miguel. 1973. Historia natural y crónica de la antigua California. Edición Miguel León Portilla.

DUBOIS, Constance Goddard. 1901. "The Mythology of the Diegueños". Journal of American. No. 14.

- 1904 "The Story of the Cahup: A Myth of the Diegueños". Journal of American Folklore. No.17.

- $1905 \mathrm{a}$ "Religious Ceremonies and Myths of the Mission Indians". American Anthropologist. No.7.

- 1905b The Mytology of the Diegueños. Mission Indians of San Diego County, California, as Proving their Status to Higher than is Generally Believed. En Proceeding of the Thirteenth Internacional Congress of Americanists. New York, 1902.

- 1907 Diegueño Myths and their Connections with the Mohave. En Preceedings of the Fifteenth International Congress Americanists, New York, 1906. Vol. 2

- 1908. The Religion of the Luiseño Indians of Southern California.University of California. American Archaeology and Ethnology, vol. 8, no 3.

GRIJALBA, Edna Aidé. 1982. "Indios y misiones: La Baja California del siglo XVIII". Calafia, vol. IV, no. 7.

HEDGES, Kenneth Everett. 1970. "An Analysis of Diegueño Pictograph". Tesis de maestría. San Diego State University.

HERSKOVITS, J. Melville. 1984. El Hombre y sus obras. Fondo de Cultura Económica.

JENSEN, Ad. E. 1986. Mito y culto entre pueblos primitivos. Fondo de Cultura Económica.

KELLY, William. 1977. Cocopá Ethnography. Anthropological Papers of the University of Arizona. Vol. 29.

LAYLANDER, Don. 1987. Sources and Strategies for the Prehistory of Baja California. Tesis de maestría, San Diego State University.

MEIGS, Peveril. 1939. The Kiliwa Indians of Lower California. Iberoamericana. Vol. 15.

- 1971. Creation myth and other reflections of the Niji Mishkwish. Pacific Coast Archaeological Society Quarterly, vol. 7, no.1.

MIXCO, Mauricio. 1977. "Textos para la etnohistoria en la frontera dominica de Baja California". Tlalocan, 7.

- 1985. Kiliwa Dietiunarg. University of Utah Anthropological Papers no. 109.

PIÑERA, David. 1978. "Inicios de la colonización civil en Baja California”. Calafia, vol. III, no. 5.

SALES, Luis. 1956. Observaciones sobre California 1772-1790. Editorial Glen Dawson. Los Ángeles. 
VENEGAS, Miguel. 1757. Noticia de la California y de su conquista temporal y espiritual hasta el tiempo presente. Madrid: M. Fernández.

- 1979. Obras californianas del padre Miguel Venegas, S.J. Universidad Autónoma de Baja California Sur. (W. Michael Mathes, Vivian C. Fisher and E. Moises Coronado, eds.). La Paz, B.C. México.

WATERMAN, T. T. 1910. "The Religious Practices of the Diegueño Indians". University of California publications en American Archaeology and Ethnology, vol. 8. 